\title{
The "Enterprises' Network Agreement": The Italian Way to Stimulate Reindustrialization for Entrepreneurial and Economic Development of SMEs
}

\author{
Andrea Cardoni ${ }^{1}$ and Lorenzo Tiacci $^{2}$ \\ ${ }^{1}$ Università degli Studi di Perugia - Dipartimento di Discipline Giuridiche e Aziendali \\ Via Pascoli, 20 - 06123 Perugia - Italy \\ ${ }^{2}$ Università degli Studi di Perugia - Dipartimento di Ingegneria Industriale \\ Via Duranti, 67 - 06125 Perugia - Italy \\ \{acardoni, lorenzo.tiacci\}@unipg.it
}

\begin{abstract}
Moving from the key features of knowledge economy and taking into consideration the new paradigms emerged in economic and managerial studies, in many countries several institutions have promoted the formation of strategic alliances to stimulate the reindustrialization and promote the national and regional development. The Italian government has recently defined a new legal framework (law n. 122/2010) to implement collaborative strategic networks through the "enterprises' network agreement". The latest data about the implementation of the new form of collaborative networks show a rapid spread of the agreement and represent an important result to read in the light of economic, managerial and industrial literature. In the paper the main characteristics of the agreement are described and discussed, and an analysis based on historical data, since two years from its introduction, is presented. The aim is to evaluate how this kind of tool can have an impact on the reindustrialization of the Country and the emergence of second generation VBE on this process.
\end{abstract}

Keywords: institutional support, enterprises' network agreement, collaborative and strategic networks, reindustrialization.

\section{Introduction}

The creation and development of collaborative networks and alliances is thought to be the best strategy to adapt the business structure to the main features of the knowledge economy, especially in the economic contexts characterized by the presence of SMEs $[1,2]$ and entrepreneurial business [3]. Moving from the key features of knowledge economy and taking into consideration the new paradigms emerged in economic and managerial studies $[4,5]$, European countries are promoting the formation of strategic alliances to stimulate the national and regional development $[6,7]$, providing institutional and financial support to companies willing to cooperate and set up a network. In the last few years, there is in Italy an increasing demand in the industrial world for concretely implement this new forms of collaborations. For example, 
demand often comes from pre-existent form of clusters or consortiums, which want to evolve to more efficient forms of collaboration [8-10]. The latest initiative of the Italian government is based on the definition of a new legal framework (law $n$. $122 / 2010$ ) to formalize the implementation of cooperation strategies: the "enterprises' network agreement" [11].

Following the most important streams of literature on strategic alliances [12-15] it is expected that this tool can generate a strong spread of CNOs strategic purposes, and can have a strong impact on the processes of economic development. The present study therefore considers all network contracts entered into since the start of the law (2010) until December 2012, analyzes their characteristics in terms of size, spatial localization and sectorial distribution and assesses the impact that this tool can have on the process of re-industrialization.

The paper is organized as follows: in section 2, a synthetic summary of the institutional and theoretical framework is reported; in section 3, the data and the methodology of the analysis is described; in section 4 we report the results of the study and discuss about the main implications; in section 5 conclusions are drawn.

\section{Institutional and Theoretical Framework}

The small size of Italian firms is a relevant limit to the achievement of greater efficiency: it often reduces the ability to change strategies, to internationalize, innovate and in general to cope with competitive pressures.

This circumstances threaten the strategic development and the performance of the Italian industrial system, still characterized by an important role played by the manufacturing business that however need to implement a process of reindustrialization based on innovation and higher critical mass, reaching only through network collaboration (Industry 2015). According to the Italian authorities all companies in Italy, but especially SME, are reluctant to cooperate, given that there were in Italy, until 2010, no effective and simple legal form of cooperation, allowing carrying out common activities (or other forms of cooperation) within a pre-defined legal framework. In this context there were spaces for public intervention in order to stimulate the creation of formal networks between undertakings as an alternative or preliminary to the growth in size. Already in 2000 the "Bologna Charter" adopted by OECD countries [7] recognized networks as an important driver of competitiveness of small enterprises and in 2008 the Small Business Act, the European Union defined lines of action to promote the development of small and medium-sized enterprises, encouraging the involvement of national governments in this area [6].

While other existing forms of legally structured cooperation, such as temporary associations of enterprises, are temporary aggregations of companies to undertake a specific operation, the contract would therefore provide the most flexible and general form of association among companies, with limited rules to ensure only transparency and stability of contractual relationships. According to Italian authorities [16] this measure was strongly demanded by Italian companies and their associations and responded to the specific structure of the Italian industry, characterized by the existence of numerous and small individually-owned companies, willing to cooperate while maintaining their independence. 
The law n.122/2010 defined the "enterprises' network agreement" as the legal tool needed to formalize strategic alliances among entrepreneurs whose "aim is to enhance, on an individual or collective basis, their innovation capabilities and their competitiveness on the market" undertaking the commitment to: i) "cooperate in different ways on a specific business related to the management of their own enterprises (or); ii) sharing information and services of an industrial, commercial, technical or technological kind (or); ii) managing in a collaborative way one or more activity included on the mission statement of the companies".

From an organizational perspective the contract can be implemented for a wide variety of collaborations, both in terms of vertical alliance, f.e. in the form of supply chain among companies that operate in the same sector at different stages of production, and horizontal alliance, f.e. among competitors sharing some special projects of innovation and strategic development. The last strategic option can be useful especially for SMEs that, though competing in their local markets, may form special alliances to reach wider markets or implement internationalization project. However, even on the structural perspective, the contract does not provide size limits and can be signed by SME's or large companies and be utilized to set up collaboration among partners with homogeneous or heterogeneous dimensions. The supporting measure consists in a tax deferral: a part of taxable revenue, targeted by participating companies for achieving the purpose of the contract and put in a specific reserve, will be excluded from the calculation of taxable income, for the duration of the contract. Such benefit is temporary, given that the money put aside for the participation to the network will be included in the tax base once the contract is fulfilled.

The contract has to be drawn according to a formal procedure with a notary, requiring an official registration with the competent Chamber of Commerce where the companies reside, and it must indicate (law n. 122/2010): i) references of partners; ii) strategic objectives; iii) performance measurement criteria to assess the progress toward strategic goals achievement; iv) network action plan; v) duration of the agreement ; v) specific endowment to manage cooperation activity.

Assessing this regulatory discipline in the light of the theoretical framework, the definition of network agreement by law n. 122/2010 is consistent with the concept of strategic network [12, 13, 17], considered as an intentional, long-term alliance enabling different companies to acquire or defend the competitive advantage against competitors outside the network. However, on the basis of an exploratory study performed on the first 50 network agreements formalized in Italy [18], it is possible to assume that the strategic objectives tend to be generic and the agreement could be better interpreted as a goal-oriented Collaborative Networked Organizations (CNOs) defined as alliance "driven by continuous production/service provision activities, characterized by a long-term duration and remaining relatively stable during that duration, with a clear definition of members' roles along the value chain". More particularly the "strategic" focus and the need to indicate the strategic goals of the alliance allow to frame the network agreement in a VBE perspective [19] defined as "strategic alliance of organizations and related supporting institutions adhering to a base long term cooperation agreement, and adopting common operating principles and infrastructures, with the main goal of increasing both their chances and their preparedness towards collaboration in potential VOs", enabling the new model to play a crucial role on manufacturing re-industrialization [20]. In this framework the 2nd 
generation VBEs that are not bound to geographical regions or specific activities and integrate their process through innovative ICT approach shall play an active role in the society/market as competitive entities [21].

\section{Data and Methodology}

The paper considers the entire population of all network agreements signed under the new legislation framework defined by the Italian government with law n. 122/2010. At December 2012 this population includes 647 agreements recorded in the official Chamber of Commerce registers, at provincial and national level (Unioncamere), characterized by the following dimensions (Tab. 1). We can note that over $20 \%$ business entities present the typical organizational structure of entrepreneurial and small enterprises (individual businesses and partnership). In addition some recent studies [22] performed on the agreements formalized until December 2011 confirmed the small and medium size of the companies involved in the contracts, employing less than 10 people on $39.2 \%$ of the cases, from 10 to 19 employees on $19.4 \%$, from 20 to 49 on $14.4 \%$ and over 50 for $12.0 \%$ of the total. Financial indicators of these companies complete the analysis and highlight the high presence of SME's, presenting the following median values: 2,708,000 € of total asset, 2,275,000 € of turnover and EBITDA margin at 7.9\%.

The data base reported for each contract the following records: name of the network, strategic goals identified, date of set-up, names of the partners involved, VAT number and the statistic code identifying the sectors and sub-sectors where the members operate.

Table 1. Population of “enterpirses' network agreements"

\begin{tabular}{lcc}
\hline & $\mathrm{N}$. & $\%$ \\
\hline - "Enterprises network agreements" & 647 & \\
Involving: & & \\
- Regions & 20 & \\
- Provinces & 99 & \\
- Entities & 3.360 & $100.0 \%$ \\
$\quad$ of which: & & \\
$\quad$ - limited companies & 2.275 & $67.7 \%$ \\
$\quad$ - partnership & 437 & $13.0 \%$ \\
$\quad$ - individual business & 350 & $10.4 \%$ \\
$\quad$ - mutual entities & 228 & $6.8 \%$ \\
- foundations and association & 10 & $0.3 \%$ \\
$\quad$ - others & 60 & $1.8 \%$ \\
\hline
\end{tabular}

Source: Chamber of Commerce - Unioncamere

Considering the classification codes according to ISTAT, macro-sector categories identified by capital letters (ex. A - Agriculture, forestry and fishing, B - Mineral mining from cave, $\mathrm{C}$ - manufacturing, etc.) and sub-sectors identified by the first two 
numbers of the code (ex. the breakdown of $\mathrm{C}$ is: 10 - food; 11 - beverage; .15 leather; etc.) the research has provided the following steps.

Firstly we adopted a single entity perspective to understand how the different sectors are represented on the population of 3,360 businesses involved in a network agreement. We compared these data with the incidence of the sectors in the population of total 5,275,515 operating businesses in Italy in order to asses if the collaborative strategy under the new legal framework is affecting the different sectors in the same proportion of the whole production system.

Secondly we moved to a networking perspective focusing on the main characteristics of the 647 CNOs resulting from the data-base in terms of dimension (number of partners) and localization (number of provinces involved). Then we analyzed the sector or the combination of sectors involved in each CNOs, focusing on those agreements that included among the partners at least one company operating in manufacturing. Indeed the literature [23] shows that the process of re-industrialization goes through a reconfiguration of the operations so that any manufacturing company that contributes to the achievement of common business objectives realizes somehow an innovative process of re-industrialization. Given the characteristics of the knowledge economy and the strategic importance of ICT we then identified those CNOs where a combination of manufacturing and ICT sectors is present. Within this group, finally, it is intended to highlight how many contracts have a geographical distribution of partners in at least at two provinces and therefore can be considered second generation VBE.

\section{Results and Discussion}

Highlighting the operating sectors of the over three thousand entities that have formalized a collaboration through the network agreement and comparing them with the distribution by sectors of the population of enterprises in Italy we get the following results (Tab. 2).

The table shows that almost half of the companies involved in networking agreement $(42.4 \%)$ operate in the manufacturing sector; at lower percentages we find the professional services $(11.0 \%)$, constructions $(9.7 \%)$ and wholesale and retail trade $(6.4 \%)$. It is worthy to note that the business entities in Italy are distributed according to different percentages, presenting an incidence of manufacturing companies involved in networks much higher than their incidence in the whole production system. This results can demonstrate a strong propensity of manufacturing SME's to collaborate, being motivated by the loss of their competitiveness and the need to identify new business opportunities through innovation.

Using the second level of ISTAT classification (sub-sectors) we elaborate a breakdown of manufacturing codes identifying the incidence of the first ten specialization inside the sector (Tab.3). The data shows an homogeneous distribution of the different manufacturing specializations between the business entities involved in network agreement and the whole population of manufacturing entities operating in Italy. This fact can demonstrate a good attitude of the new formal setting based on collaborative strategy to reflect the traditional vocation of Italian specializations 
reinforcing the strengths and safeguarding the values of entrepreneurial SME's operating in manufacturing industries.

Table 2. Breakdown of sectors - incidence comparison

\begin{tabular}{lcr}
\hline & \multicolumn{2}{c}{ Business entities } \\
\hline & $\begin{array}{c}\text { involved in network } \\
\text { agreement }\end{array}$ & in Italy \\
\hline Manufacturing & $42.4 \%$ & $10.2 \%$ \\
Professional. scientific and technical activities & $11.0 \%$ & $3.3 \%$ \\
Constructions & $9.7 \%$ & $15.7 \%$ \\
Wholesale and retail trade & $7.4 \%$ & $27.0 \%$ \\
Information and communication services & $6.4 \%$ & $2.1 \%$ \\
Agriculture. forestry and fishing & $4.8 \%$ & $15.7 \%$ \\
Arts. sports. entertainment and recreation & $3.6 \%$ & $1.1 \%$ \\
Rental. travel agencies. business support services & $2.9 \%$ & $2.7 \%$ \\
Health 'and social work & $2.5 \%$ & $0.6 \%$ \\
Transportation and storage & $2.0 \%$ & $3.1 \%$ \\
Others & $6.2 \%$ & $18.5 \%$ \\
\hline
\end{tabular}

Table 3. Breakdown of manufacturing sub-sectors - incidence comparison

\begin{tabular}{lcc}
\hline & \multicolumn{2}{c}{ Business entities } \\
\hline & $\begin{array}{c}\text { involved in "network } \\
\text { agreement" }\end{array}$ & in Italy \\
\hline Metal product (except mach. and equip.) & $17.4 \%$ & $20.0 \%$ \\
Machinery and equipment & $11.8 \%$ & $6.0 \%$ \\
Food industries & $8.4 \%$ & $10.5 \%$ \\
Leather and related & $7.6 \%$ & $4.1 \%$ \\
Computer products and electr. And optics & $4.8 \%$ & $2.2 \%$ \\
Electrical and equipment for household & $4.7 \%$ & $2.7 \%$ \\
Other manufacturing & $4.4 \%$ & $7.9 \%$ \\
Other products & $4.3 \%$ & $5.2 \%$ \\
Furniture manufacture & $3.8 \%$ & $4.8 \%$ \\
Rubber and plastic & $3.8 \%$ & $2.3 \%$ \\
\hline
\end{tabular}

Moving to analyze the data-base of agreements adopting a networking perspective we studied the main features of CNOs formalized under the legislative framework defined be Law n. 122/2010, focusing on the dimension (number of partners involved per CNOs) and localization (number of provinces involved per network) as resulting in the following table (Tab. 4). Most of the networks (over 70\%) includes from two to five members, representing therefore a form of alliance where the coordination and trust mechanisms tend to affect few partners and the strategic focus can benefit of a concentrated collaborative framework. In terms of localization over $30 \%$ of the networks are very geographically characterized, involving only one province and 
probably reflecting the model of the old industrial districts. However, a significant proportion of network includes members that are localized in two or more provinces, meaning a tendency to build network relations not characterized by territorial proximity that are able to create new space of collaboration over geographically diversified areas.

Table 4. Dimension and localization of CNOs formalized with the network agreement

\begin{tabular}{|c|c|c|c|}
\hline \multicolumn{2}{|c|}{ Dimension of CNOs } & \multicolumn{2}{c|}{ Localization of CNOs } \\
\hline $\begin{array}{c}\text { N. of partners } \\
\text { involved per "network } \\
\text { agreement" }\end{array}$ & $\%$ & $\begin{array}{c}\text { N. of provinces } \\
\text { involved per } \\
\text { "network agreement" }\end{array}$ & $\%$ \\
\hline$/$ & $/$ & 1 & $36.1 \%$ \\
\hline 2 & $15.5 \%$ & 2 & $29.3 \%$ \\
\hline 3 & $25.7 \%$ & 3 & $17.1 \%$ \\
\hline 4 & $19.2 \%$ & 4 & $8.2 \%$ \\
\hline 5 & $11.6 \%$ & 5 & $3.6 \%$ \\
\hline 6 & $3.8 \%$ & 6 & $2.6 \%$ \\
\hline$>=7$ & $24.2 \%$ & $>=7$ & $3.3 \%$ \\
\hline
\end{tabular}

Moving to analyze the industrial features of CNOs formalized through the "network agreement" we considered the combination of different sectors of the partners, focusing on those networks operating in manufacturing (Tab.5). It is worthy to observe that almost two-thirds of the contractual CNOs (69\%) includes at least one company that operates in manufacturing; inside this sample approximately the $40 \%$ presents over a half of industrial incidence on the alliance.

Focusing on the forms of networking that may have greater potential to successfully start the process of re-industrialization, we search for those networks including the joint presence of companies operating in manufacturing and ICT and we obtained n. 83 CNOs $(12.8 \%$ on the total). Combining these dimension with the localization perspective we found out n. 71 CNOs Manufacturing \& ICT involving more than one provinces that can be considered as second generation of VBE.

Table 5. CNOs for reindustrialization

\begin{tabular}{lcc}
\hline & N. & $\%$ \\
\hline $\begin{array}{l}\text { - CNOs involving Manufacturing partners } \\
\text { of which: }\end{array}$ & 446 & $69.0 \%$ \\
$-\quad$ Manufacturing (Man) companies 100\% & 55 & $12.3 \%$ \\
$-\quad$ Man < 50\% & 127 & $28.4 \%$ \\
$\quad 264$ & $59.1 \%$ \\
- CNOs involving Man \& ICT partners & 83 & $12.8 \%$ \\
$\begin{array}{l}\text { - CNOs involving Man \& ICT \& whose partners are } \\
\text { dislocated in more than 2 Provinces }\end{array}$ & 71 & $8.7 \%$ \\
\hline
\end{tabular}


By analyzing the sectors involved in this set of CNOs (Tab. 6) it is possible to note a high degree of sectors diversification, higher than to the totality of the networks involved in the agreement. This confirms that particularly this type of CNOs can assume a strategic role in the innovative recombination of operations and in the reindustrialization of the Italian economy.

Table 6. Sectors differentiation

\begin{tabular}{|c|c|c|}
\hline $\begin{array}{c}\text { Number of } \\
\text { different } \\
\text { sectors per network }\end{array}$ & $\begin{array}{c}\text { Incidence on } \\
\text { second generation } \\
\text { VBEs }\end{array}$ & $\begin{array}{c}\text { Incidence } \\
\text { on the total }\end{array}$ \\
\hline 2 & $21.13 \%$ & $32.2 \%$ \\
\hline 3 & $25.35 \%$ & $31.6 \%$ \\
\hline 4 & $33.80 \%$ & $19.2 \%$ \\
\hline 5 & $7.04 \%$ & $9.6 \%$ \\
\hline$>=6$ & $12,7 \%$ & $4.3 \%$ \\
\hline
\end{tabular}

\section{Summary}

In the paper a new legal framework named "enterprises' networks agreement", introduced in 2010 by the Italian Government, has been described, and the latest data about the implementation of the new form of collaborative network have been presented. Based on the institutional and theoretical perspective it is possible to argue that the network agreement has been implemented as a strategic tool of industrial policy, able to facilitate the contractual arrangement of the alliances and considered as a vehicle of institutional support to develop the managerial innovations for a new culture of collaboration.

Analyzing the empirical data it can be observed that, since its introduction, the network agreement shows an interesting spread, reaching to December 2012 a total of 647 contracts that involve more than three thousand businesses. This result has already triggered an important innovation process involving all major stakeholders of the Italian economic system (national and regional institutions, business associations, banks, professionals, managers) that are now defining specific measures to stimulate institutional, financial and managerial schemes and tools to support network formation. For this reason, the introduction of the network agreement has certainly achieved the result to define an institutional framework capable of triggering the "leverage" of cultural innovation.

In terms of business performance it is still too early to evaluate the ability of the new formal arrangement to remove the limits of the small size developing the potential benefits of partnerships on liabilities, IP protection and industrial development strategy. Instead, studying the characteristics of the network in terms of sectorial composition, size and geographical location, the paper demonstrates that the contract has the potential to really stimulate re-industrialization and innovation.

Results show that manufacturing companies are particularly involved in the formation of the new type of $\mathrm{CNO}$, being the entire sector well represented in each of its specialization (sub-sector). With respect to earlier collaborative forms developed in 
Italy, like Industrial Districts and Consortia, the new form shows a much higher degree of sectors diversification, and is much less characterized by the geographical concentration, being relevant the number of networks involving different provinces spread over the Italian territory. There are also a number of networks that add to these two characteristics (diversification and de-localization) the joint presence of manufacturing and ICT sectors. The networks of this type are candidates to become the so called ' 2 nd generation VBE', and seem to have the characteristics to play a relevant role in the reindustrialization of the Italian economy.

\section{References}

1. Macpherson, A., Holt, R.: Knowledge, learning and small firm growth: A systematic review of the evidence. Res. Policy 36, 172-192 (2007)

2. Donkels, R., Lambrecht, J.: Network and small business growth: An explanatory model. Small Business Economics, 273-289 (1995)

3. Parker, S.C.: The economics of formal business networks. J. Bus. Venturing 23, 627-640 (2008)

4. Etzkovitz, H.: The Triple Helix. Routledge, London (2008)

5. Johanson, M., Lundberg, H.: Network Strategies for Regional Growth. Palgrave MacMillan, New York (2011)

6. Cafaggi, F.: Contractual Networks and the Small Business Act: Towards European Principles? European Review of Contract Law 4, 493-539 (2008)

7. OECD: The Bologna charter on SME policies. In: Enhancing SME Competitivness: The OECD Bologna Ministerial Conference (2000)

8. Cardoni, A., Saetta, S., Tiacci, L.: Evaluating how potential pool of partners can join together in different types of long term collaborative networked organizations. In: Camarinha-Matos, L.M., Boucher, X., Afsarmanesh, H. (eds.) PRO-VE 2010. IFIP AICT, vol. 336, pp. 312-321. Springer, Heidelberg (2010)

9. Tiacci, L., Cardoni, A.: How to move from traditional to innovative models of networked organizations: A methodology and a case study in the metal-mechanic industry. In: Camarinha-Matos, L.M., Pereira-Klen, A., Afsarmanesh, H. (eds.) PRO-VE 2011. IFIP AICT, vol. 362, pp. 413-420. Springer, Heidelberg (2011)

10. Saetta, S., Tiacci, L., Cagnazzo, L.: The innovative model of the Virtual Development Office for collaborative networked enterprises: the GPT network case study. Int. J. Comput. Integ. M 26, 41-54 (2013)

11. Cafaggi, F.: Il contratto di rete, Il Mulino, Bologna (2009)

12. Jarrillo, J.C.: On Strategic Networks. Strategic Management Journal 9, 31-41 (1988)

13. Gulati, R.: Managing Network Resources. In: Alliances, Affiliations, and other Relational Assets. Oxford University Press (2007)

14. Romero, D., Galeano, N., Molina, A.: Virtual organisation breeding environments value system and its elements. J. Intell. Manuf. 21, 267-286 (2010)

15. Romero, D., Molina, A.: Collaborative networked organisations and customer communities: Value co-creation and co-innovation in the networking era. Prod. Plan. Control 22, 447-472 (2011)

16. European Commission: State Aid n. 343/2010 - Support to set up companies networks (reti di impresa) (2011) 
17. Ricciardi, A.: Strategie di cooperazione tra aziende e mitigazione del rischio operativo: i vantaggi competitivi delle reti di imprese. Scritti in Onore di Vittorio Coda, Egea, Milano (2010)

18. Cardoni, A.: Business planning and management accounting in strategic networks: theoretical development and empirical evidence from enterprises network agreement. Management Control 3, 91-116 (2012)

19. Camarinha-Matos, L.M., Afsarmanesh, H.: A framework for virtual organization creation in a breeding environment. Annu. Rev. Control 31, 119-135 (2007)

20. Camarinha-Matos, L.M.: Collaborative networked organizations: Status and trends in manufacturing. Annu. Rev. Control 33, 199-208 (2009)

21. Afsarmanesh, H., Camarinha-Matos, L.M., Msanjila, S.S.: On management of 2nd generation Virtual Organizations Breeding Environments. Annu. Rev. Control 33, 209-219 (2009)

22. Bentivogli, C., Quintiliani, F., Sabbatini, D.: Le reti di imprese. In: Questioni di Economia e Finanza - Occasional Papers, Banca d'Italia, vol. 152 (2013)

23. Cool, K.O., Henderson, J.E., Abate, R.: Restructuring strategy: new networks and industry challenges. Wiley-Blackwell (2004) 